\title{
Headache disorders in a tertiary care headache outpatient clinic in Austria
}

\author{
M Fischer ${ }^{*}, \mathrm{G}$ Wille, S Klien, G Broessner \\ From The European Headache and Migraine Trust International Congress \\ London, UK. 20-23 September 2012
}

\section{Background}

Headache is a common cause of medical consultation, both in primary care and in specialist neurology outpatient clinics. This study analyzed the incidence and characteristics of headache patients during an 18-month period in a tertiary care headache outpatient clinic.

\section{Material and methods}

Patients visiting a tertiary care headache outpatient clinic at the University Hospital Innsbruck, Austria, were registered consecutively. Diagnosis of primary and secondary headache disorders was in accordance with the revised version of the International Headache Classification (ICHD-II) and data including age, sex, Headache Impact Test (HIT-6), headache frequency, trigger factors and caffeine intake were collected prospectively over an 18-month period.

\section{Results}

From December 2010 until April 2012626 patients comprising 897 visits were registered in our headache database. The female to male ratio was 3:1. The median age accounted for 40.7 years (IQR: 28.3 "C 50.4). Diagnoses of primary headache disorders were grouped as follows: migraine $61 \%$ (episodic migraine with aura $22 \%$, episodic migraine without aura $37 \%$, chronic migraine $2 \%$ ), episodic $(12 \%)$ and chronic tension-type headache $(8 \%)$, trigeminal autonomic cephalalgias (4\%), other primary headaches (1\%), secondary headaches (13\%),cranial neuralgias and facial pain $(2 \%)$ and currently unclassified (15\%). The majority of patients with secondary headache disorders were diagnosed with headache attributed to a substance or its withdrawal (10\%) The median number of headache days per month was 8 (IQR 4-20). 33\% of all patients reported $>15$ headache days during the previous month.

\section{Conclusions}

This registry reflects the characteristics of patients seen in an outpatient headache clinic. In accordance with other data from tertiary hospitals migraine was the most common diagnosis in our outpatient clinic followed by tension-type headache. Almost 33\% suffered from frequent (¡Ý15 days per month) headache reflecting a substantial and growing patient population with medico-economical burden to the headache community.

Published: 21 February 2013

doi:10.1186/1129-2377-14-S1-P30

Cite this article as: Fischer et al:: Headache disorders in a tertiary care headache outpatient clinic in Austria. The Journal of Headache and Pain 2013 14(Suppl 1):P30.
Submit your manuscript to a SpringerOpen ${ }^{\circ}$ journal and benefit from:

- Convenient online submission

- Rigorous peer review

- Immediate publication on acceptance

- Open access: articles freely available online

- High visibility within the field

- Retaining the copyright to your article

Submit your next manuscript at $>$ springeropen.com 